\title{
Specific surface area determinations for microporous/mesoporous materials: the case of mesoporous FAU-Y zeolites
}

\author{
Anne Galarneau ${ }^{1 *}$, Dirk Mehlhorn, ${ }^{1}$ Flavien Guenneau, ${ }^{2}$ Benoit Coasne, ${ }^{3}$ Francois \\ Villemot, ${ }^{4}$ Delphine Minoux, ${ }^{5}$ Cindy Aquino, ${ }^{5}$ Jean-Pierre Dath. ${ }^{5}$
}

\author{
${ }^{1}$ ICGM UMR 5253 CNRS - Univ Montpellier - ENSCM, ENSCM 240 Av Pr E. Jeanbrau, 34296 \\ Montpellier cedex 5, France. \\ ${ }^{2}$ Sorbonne Université, CNRS, Collège de France, Laboratoire de Chimie de la Matière \\ Condensée, LCMCP, F-75005 Paris, France. \\ ${ }^{3}$ Laboratoire Interdisciplinaire de Physique (LIPhy), CNRS and University Grenoble Alpes, 140 \\ rue de la Physique, Domaine Universitaire, BP 87, 38402 Saint Martin d'Heres Cedex. \\ ${ }^{4}$ CEA/Saclay, NIMBE, LIONS, 91191 Gif sur Yvette Cedex, France. \\ ${ }^{5}$ Total Research\&Technology Feluy, Belgium.
}

*E-mail: anne.galarneau@enscm.fr

\begin{abstract}
Keywords: micropore surface, mesopore surface, t-plot, BET equation, hierarchical material, nitrogen isotherm, H-Y, MCM-41
\end{abstract}

\begin{abstract}
A methodology for determining from $\mathrm{N}_{2}$ adsorption isotherms at $77 \mathrm{~K}$ the micropore, mesopore, and external surface areas of hierarchical microporous/mesoporous
\end{abstract}


materials is described. For FAU-Y zeolite, the microporous surface area calculated using the Rouquerol criterion and the BET equation is in accord with the geometrical surface determined by the chord length distribution method. Therefore BET surface area $\left(\mathrm{S}_{\mathrm{BET}}\right)$ is well representative of micropore surface areas of microporous materials and of total surface area of microporous/mesoporous materials. Mechanical mixtures of mesoporous MCM-41 and microporous FAU-Y powders of known surface areas were used to calculate the respective surface areas by weighted linear combination and the results were compared to the values obtained by the t-plot method. The first slope of the t-plot determined the mesopore + external surface areas $\left(\mathrm{S}_{\text {mes+ext }}\right)$. The linear fit of the first slope is in general in the range $0.01<\mathrm{p} / \mathrm{p}_{0}<0.17$ and contains the volumes and relative pressures at which all micropores are filled $\left(\mathrm{p} / \mathrm{p}_{0}>0.10\right)$. Overestimation of $\mathrm{S}_{\text {mestext }}$ values was evident and appropriate corrections were provided. External surface areas $\left(\mathrm{S}_{\mathrm{ext}}\right)$ were obtained from the second slope of the t-plot, without noting an overestimation of $\mathrm{S}_{\mathrm{ext}}$, thus allowing the determination of mesopore surface areas $\left(\mathrm{S}_{\mathrm{mes}}\right)$ by difference. Micropore surface areas were calculated by subtracting $\mathrm{S}_{\text {mes+ext }}$ from the total surface area, $\mathrm{S}_{\mathrm{BET}}$. As an example, this methodology was applied to the characterization a family of hierarchical microporous/mesoporous FAU-Y (FAUmes) synthesized from H-FAU-Y (H-Y, $\mathrm{Si} / \mathrm{Al}=15)$ using $\mathrm{C} 18 \mathrm{TAB}$ as surfactant and different $\mathrm{NaOH} / \mathrm{Si}$ ratio $(0.05<\mathrm{NaOH} / \mathrm{Si}<0.25)$. By increasing the $\mathrm{NaOH} / \mathrm{Si}$ ratio in synthesis of FAUmes, it was shown that as the micropore surface area decreases, the mesopore surface area increases, while the micropore + mesopore surface area remains constant. This methodology allows accurate characterization of the surface areas of microporous/mesoporous materials. 


\section{INTRODUCTION}

Microporous materials such as zeolites, metal-organic frameworks, and porous carbons are widely used in catalysis, separation, selective adsorption, and metal decontamination. ${ }^{1,2}$ These applications benefit from the large surface areas and small pore sizes of these materials, leading to strong interactions with the surface. However, these materials suffer from internal diffusion limitation due to the small size of their pores, which limits their efficiency. ${ }^{1}$ In Order to increase the transport in microporous materials, mesopores have been created to produce micro/mesoporous materials. ${ }^{3-7}$ One simple way to create mesopores in microporous zeolites consists of a post-treatment in basic medium with alkyltrimethylammonium surfactants. ${ }^{8-10}$ Such hierarchical structures retain the micropores needed for a specific application and provide improved transport properties due to the presence of mesopores. The portions of micropore and mesopore surfaces are key factors to better understand these materials, which most of the time are characterized by their specific surface areas.

There are two main tools to calculate specific surface areas from adsorption measurements: the BET equation and the t-plot method, both being subject to controversy for materials containing micropores. ${ }^{11-16}$ The t-plot method is a widely used procedure to estimate the total surface area as well as the external surface area of materials. In this method, the average thickness of an adsorbed film is first determined for a reference material containing no porosity, or only macroporosity, and having the same surface chemistry as the studied porous material. Then the so-called t-plot is created by plotting the adsorbed volume at a given pressure against the average thickness of the adsorbate film $(\mathrm{t})$ obtained at the same pressure for the non-porous 
reference material. ${ }^{15,16}$ For mesoporous materials, the adsorbed volume (V) varies linearly with the film thickness $(t)$ and passes through the origin. The total surface area $\left(\mathrm{S}_{\mathrm{tot}}\right)$ is directly given by the slope of the first linear fit at low pressure with $\mathrm{V}=\mathrm{S}_{\text {tot }} \mathrm{t}$. Once all pores are filled, adsorption occurs only on the external surface of the material and leads to a second linear fit at high pressure, the slope of which allows the determination of the external surface $\left(\mathrm{S}_{\mathrm{ext}}\right)$ with $\mathrm{V}=$ $\mathrm{S}_{\mathrm{ext}} \mathrm{t}$.

For materials containing micropores, the first linear fit of the t-plot at low pressure most of the time does not pass through the origin or is not linear at very low pressure. ${ }^{15}$ The first linear fit is done using several data points and the intercept with the Y-axis is usually taken to be the micropore volume. However, it was demonstrated experimentally in a previous publication ${ }^{12}$ that the t-plot method underestimates the micropore volume when it exceed more than $10 \%$ of the total pore volume. By modeling, it also was highlighted that the t-plot method overestimates the surface areas of hierarchical microporous/mesoporous materials, such as mesoporous MOF structures $(\mathrm{CuBTC}) .{ }^{13}$ One goal of the present study is to verify experimentally this observation of overestimation of surface area by t-plot analysis.

To analyze carefully micropore and mesopore surface areas in a material by the t-plot method, it is of prime importance to use a good reference isotherm with the same surface chemistry as the analyzed materials. Different models of film thickness (e.g., Harkins and Jura, Halsey, Lecloux, etc) have been proposed in the literature. ${ }^{16}$ But none of them are accurate for porous silica. As shown previously for purely mesoporous MCM-41 silica with a mesopore diameter of $4 \mathrm{~nm}$, the t-plots do not pass through the origin. ${ }^{12}$ Consequently, reference isotherms for materials of similar surface chemistry first need to be established. Toward this end, reference isotherms have been recorded for different types of non-porous ${ }^{12}$ and macroporous silica ${ }^{17}$ and all of them are available for t-plot analysis of porous silica-based materials. 
Another way to calculate total surface area is to fit the adsorption data to the BET equation. This is a routine characterization technique for porous materials. ${ }^{11,14-16}$ The BET specific surface area $\left(\mathrm{S}_{\mathrm{BET}}\right)$ is usually assessed from adsorption experiments prior to capillary condensation of the fluid. The hypothesis of the BET model is that (1) adsorption occurs on energetically homogeneous sites and (2) molecules can adsorbed on each other. ${ }^{11,14-16}$ In this case, the adsorption energy for all molecules adsorbed above the first layer is constant and equal to the cohesion energy in the bulk liquid. The pressure range used to estimate the BET surface should follow the Rouquerol criterion, ${ }^{11,14,15,18}$ which makes use of the adsorption data up to the $\mathrm{p} / \mathrm{p}_{0}$ pressure where $\mathrm{V}\left(1-\mathrm{p} / \mathrm{p}_{0}\right)$ exhibits a maximum. Adsorption beyond this value represents the point where the adsorbed amount increases less rapidly with pressure in comparison to the first adsorbed layer. ${ }^{15}$

The resulting monolayer capacity $\mathrm{V}_{\mathrm{m}}$ obtained from the BET plot provides a reasonable estimate of the geometrical surface when $V_{m}$ is converted to surface area using the common value of $0.162 \mathrm{~nm}^{2}$ for the molecular cross section of nitrogen. ${ }^{15}$ However, care should be taken when using this approach. Depending on the surface chemistry of the material, the ovoid nitrogen molecules can pack differently on the surface. The effective cross sections for nitrogen, for instance, can varying from $0.135 \mathrm{~nm}^{2}$ for hydroxylated silica surfaces to $0.162 \mathrm{~nm}^{2}$ for hydrophobic surfaces. ${ }^{19}$

The present study is in two parts. The first part concerns the use of the BET equation and the t-plot method to assess surface areas for micro-/mesoporous materials. The surface area determined by the BET equation for microporous FAU-Y zeolite is compared to the geometrical calculation of the surface by chord length distribution. The surface areas for micro-/mesoporous samples are compared to the areas determined by linear combination of the adsorption data for mechanical mixtures of FAU-Y and MCM-41 with known micropore and mesopore surface 
areas, respectively. A methodology is proposed to decouple the micropore, mesopore and external surface areas of the materials.

In the second part of this study, the corrected surface areas determined from the t-plots of mechanical mixtures of MCM-41 and FAU-Y are used to obtain the micropore and mesopore surfaces of a family of hierarchical micro-/mesoporous FAU-Y materials (denoted FAUmes) synthesized by post-treatment of FAU-Y in presence of octadecyltrimethylammonium (C18TAB) surfactant in basic medium at different $\mathrm{NaOH} / \mathrm{Si}$ ratios $(0.05<\mathrm{NaOH} / \mathrm{Si}<0.25)$.

\section{EXPERIMENTAL SECTION}

Synthesis of mesoporous FAU-Y (FAUmes). In a beaker $(250 \mathrm{~mL})$, x g of NaOH pellets $(\mathrm{x}=0.199-1.998 \mathrm{~g})$ was added to $180 \mathrm{~g}$ of $\mathrm{H}_{2} \mathrm{O}$ and the mixture was magnetically stirred until complete dissolution at room temperature $\left(25^{\circ} \mathrm{C}\right)$. Then $7.843 \mathrm{~g}$ of octadecyltrimethylammonium bromide $(\mathrm{C} 18 \mathrm{TAB})$ was added and stirring was continued until dissolution was again complete. The magnetic stirrer was then replaced by an endless screw stirrer, which is more gentle and necessary to keep the particle size and shape of the initial particles. The endless screw stirrer was described previously for the pseudomorphic transformation of silica particles into MCM-41 particles. ${ }^{20}$ Then $12 \mathrm{~g}$ of the parent dealuminated H-FAU-Y zeolite ( $\left.\mathrm{Si} / \mathrm{Al}=15\right)$, obtained from Zeolyst under the trade name CBV720, was then added and the mixture stirred for $1-2 \mathrm{~h}$ at room temperature $\left(25^{\circ} \mathrm{C}\right)$ to obtain a homogeneous white suspension. The suspension was then transferred into a Teflon-lined stainless-steel autoclave $(250 \mathrm{~mL})$ and kept under static conditions for 20 hours at $115{ }^{\circ} \mathrm{C}$. The resulting mixture was then filtered and washed with water until neutral $\mathrm{pH}$. The sample was dried in an oven at $80{ }^{\circ} \mathrm{C}$ for $12 \mathrm{~h}$ and calcined at $550{ }^{\circ} \mathrm{C}$ for $8 \mathrm{~h}$ 
(heating rate $5{ }^{\circ} \mathrm{C} / \mathrm{min}$ ). The molar ratios of the reaction mixtures were $1.0 \mathrm{FAU}-\mathrm{Y} / 0.10$ $\mathrm{C} 18 \mathrm{TAB} / n \mathrm{NaOH} / 50 \mathrm{H}_{2} \mathrm{O}(n=0.025-0.25)$.

Synthesis of MCM-41. Al-MCM-41(C16, Si/Al = 15), used in the preparation of mechanical mixtures of FAU-Y and MCM-41, was synthesized as follows. $\mathrm{NaAlO}_{2}$ (Carlo Erba) was added to an alkaline solution containing cetyltrimethylammonium bromide surfactant (C16TAB) (Aldrich). The mixture was stirred at $50{ }^{\circ} \mathrm{C}$ until complete dissolution before adding Aerosil 200 silica (Degussa) and stirring for $1 \mathrm{~h}$. The composition of the mixture in molar ratio is $1 \mathrm{SiO}_{2} / 0.07 \mathrm{NaAlO}_{2} / 0.1 \mathrm{C} 16 \mathrm{TAB} / 0.25 \mathrm{NaOH} / 50 \mathrm{H}_{2} \mathrm{O}$. The slurry was then placed in a stainless-steel autoclave and heated at $115^{\circ} \mathrm{C}$ for $24 \mathrm{~h}$. The resulting material was then filtered and washed until neutral $\mathrm{pH}$, dried at $80{ }^{\circ} \mathrm{C}$, and calcined at $550{ }^{\circ} \mathrm{C}$ for $8 \mathrm{~h}$ under air-flow.

Materials Characterization. $\mathrm{N}_{2}$ adsorption isotherms at $77 \mathrm{~K}$ were measured on a Belsorb apparatus using 200-300 mg samples outgassed in vacuum at $250{ }^{\circ} \mathrm{C}$ for $12 \mathrm{~h}$ before analysis. Ar adsorption isotherms at $87 \mathrm{~K}$ were obtained on a Quantachrome Autosorb-1C apparatus. The 50 -mg samples were outgassed under vacuum at $200{ }^{\circ} \mathrm{C}$ for $20 \mathrm{~h}$ before analysis.

\section{RESULTS AND DISCUSSION}

Surface areas of FAU-Y and MCM-41. The nitrogen sorption isotherms at $77 \mathrm{~K}$ of FAU-Y and MCM-41 are reported in Figure 1 and t-plot curves are provided in Figure 2. The surface areas of FAU-Y and MCM-41 were determined using the BET equation and the t-plot method. 

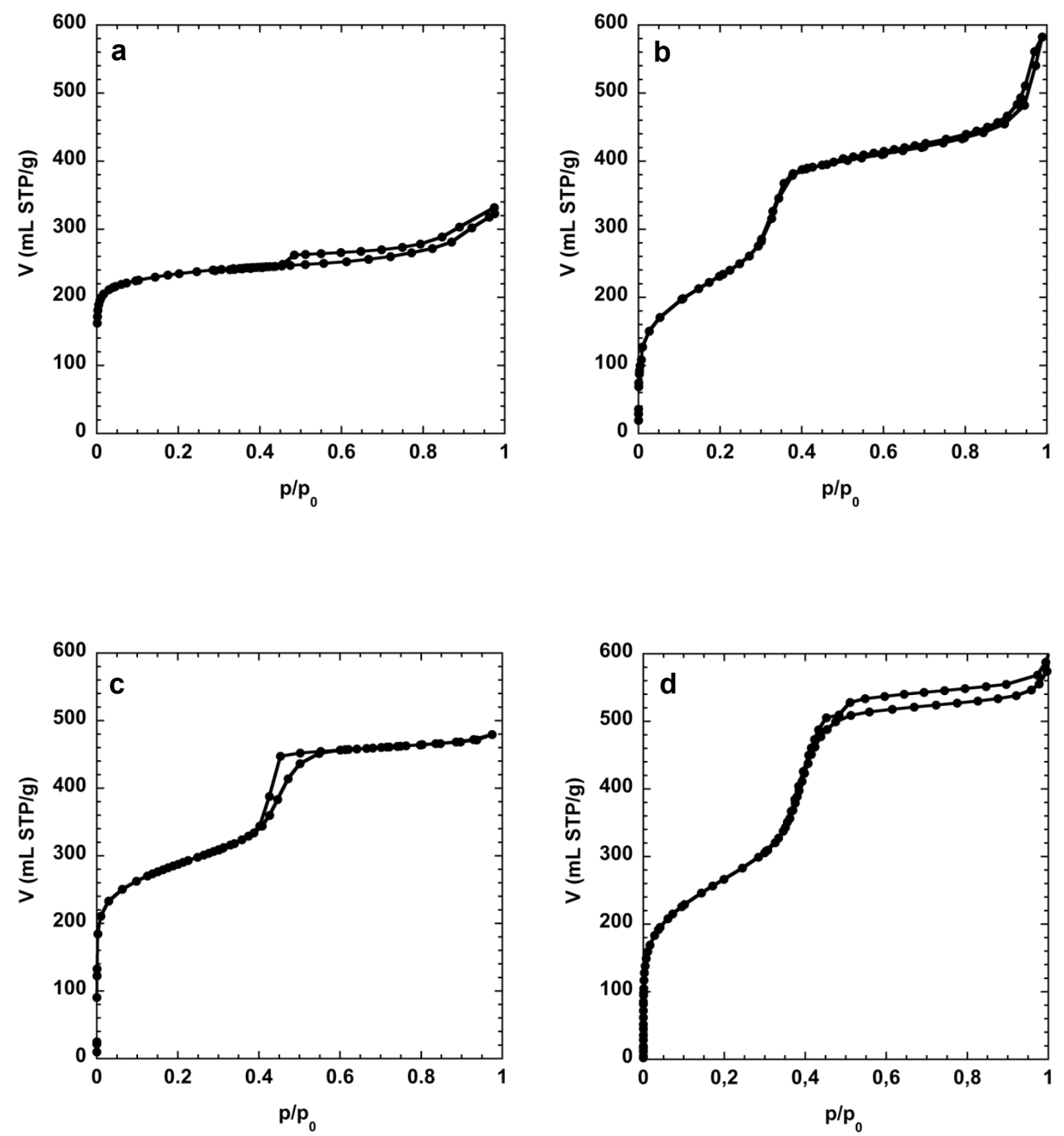

Figure 1. Nitrogen sorption isotherms at $77 \mathrm{~K}$ of (a) H-FAU-Y (Si/Al = 15) (CBV720), (b) AlMCM-41(C16) $(\mathrm{Si} / \mathrm{Al}=15)$ and hierarchical microporous/mesoporous Na-FAU-Y $(\mathrm{Si} / \mathrm{Al}=15)$, named FAUmes, synthesized from H-FAU-Y and C18TAB surfactant with different $\mathrm{NaOH} / \mathrm{Si}$ ratio (c) FAUmes $-\mathrm{NaOH} / \mathrm{Si}=0.10$ and (d) FAUmes $-\mathrm{NaOH} / \mathrm{Si}=0.25$. 

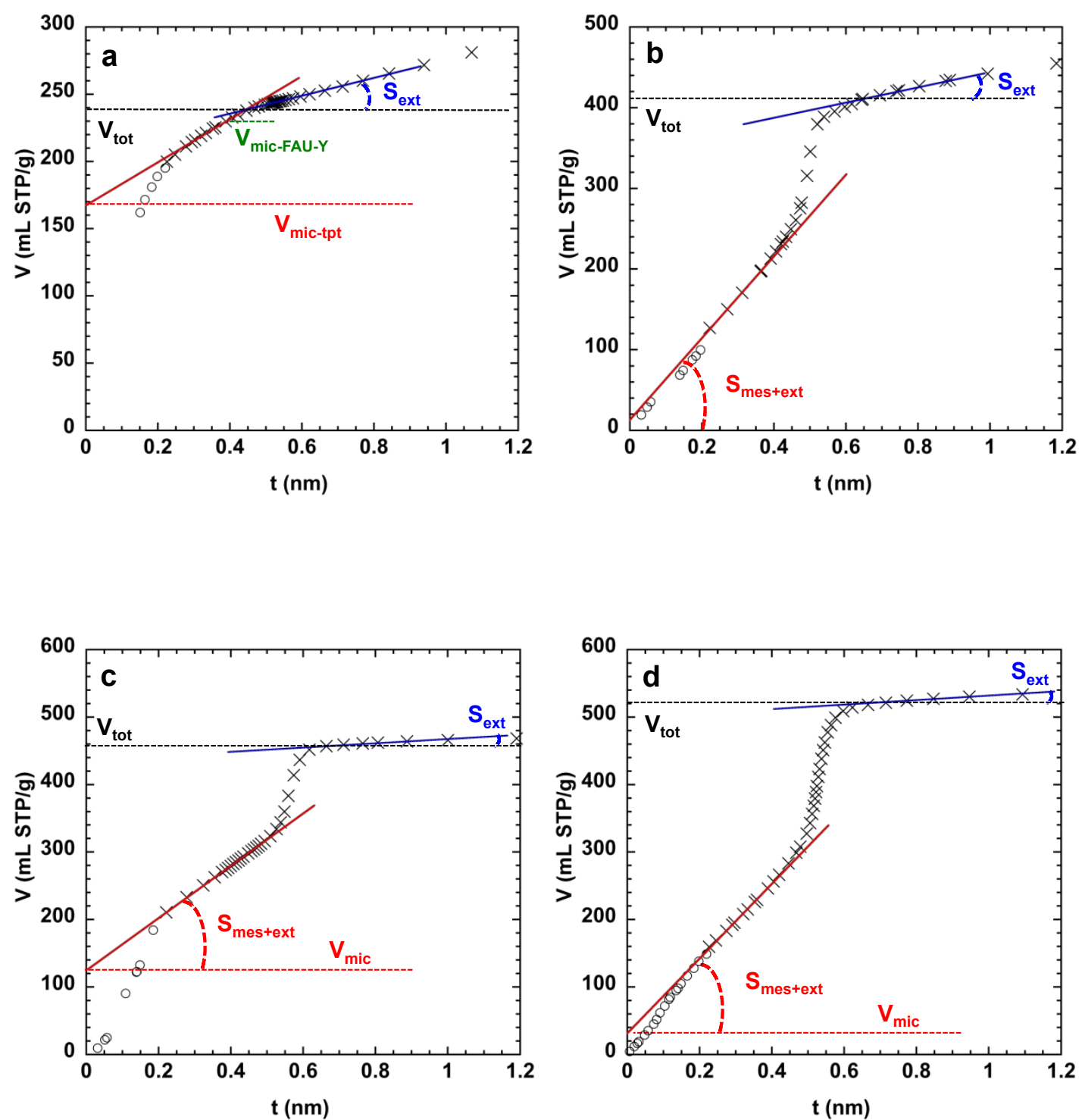

Figure 2. t-plot curves of (a) H-FAU-Y (Si/Al = 15) (CBV720), (b) Al-MCM-41(C16) $(\mathrm{Si} / \mathrm{Al}=$ 15) and hierarchical microporous/mesoporous Na-FAU-Y $(\mathrm{Si} / \mathrm{Al}=15)$ synthesized from H-FAU$\mathrm{Y}$ and $\mathrm{C} 18 \mathrm{TAB}$ surfactant with different $\mathrm{NaOH} / \mathrm{Si}$ ratio (c) FAUmes(C18) $-\mathrm{NaOH} / \mathrm{Si}=0.10$ and (d) FAUmes $(\mathrm{C} 18)-\mathrm{NaOH} / \mathrm{Si}=0.25$. t-plots were produced using (crosses) Aerosil 200 as reference isotherm and fitted by Eq. $5-7$ for the pressure range $0.01<\mathrm{p} / \mathrm{p}_{0}<0.80$. For the low 
pressure range $\left(\mathrm{p} / \mathrm{p}_{0}<0.01\right)$ t-plots were produced using (circles) LiChrospher $1000(\mathrm{Si1000})$ as reference isotherm described by Jaroniec et al. ${ }^{17}$ (see supporting informations for the equations).

The BET surface areas have been calculated using the Rouquerol criterion. ${ }^{11}$ The Rouquerol plot, which is $\mathrm{V}\left(1-\mathrm{p} / \mathrm{p}_{0}\right)$ as a function of $\mathrm{p} / \mathrm{p}_{0}$, has been plotted to identify the first maximum pressure useful for a linear fit to the BET equation (Eq. 1).

$$
\frac{p / p_{0}}{V\left(1-p / p_{0}\right)}=\frac{1}{V_{m} C}+\frac{C-1}{V_{m} C}\left(p / p_{0}\right)
$$

The adsorption data are then fit to the BET equation (Eq. 1) by a linear regression $(y=a x+b)$. The slope $a$ and the intercept $b$ are used to calculate the monolayer volume $\left(\mathrm{V}_{\mathrm{m}}\right)$ and then the BET surface area $\left(\mathrm{S}_{\mathrm{BET}}\right)$ with the following equations (Eq. 2,3):

$\mathrm{V}_{\mathrm{m}}=1 /(\mathrm{a}+\mathrm{b})$

$$
S_{B E T}=\sigma_{N_{2}} \frac{V_{m}}{V_{N_{2}}} \mathcal{N}_{A}
$$

where $\mathrm{V}_{\mathrm{N} 2}$ is the molar gas volume, $\mathrm{N}_{\mathrm{A}}$ is Avogadro number, and $\sigma_{\mathrm{N} 2}$ is the cross-section of the $\mathrm{N}_{2}$ molecule, which corresponds experimentally to (Eq. 4) for $\sigma_{\mathrm{N} 2}=0.162 \mathrm{~nm}^{2}$ :

$$
\mathrm{S}_{\mathrm{BET}}\left(\mathrm{m}^{2} / \mathrm{g}\right)=4.36 \mathrm{~V}_{\mathrm{m}}(\mathrm{mL} \mathrm{STP})
$$


For MCM-41, the BET surface area was $843 \mathrm{~m}^{2} / \mathrm{g}$.

The use of BET equation for microporous materials surface analysis is subject to controversy. However, computational studies of hierarchical micro-/mesoporous MOF materials (e.g., CuBTC) demonstrated that the BET surface area is well representative of the total surface area (micropore + mesopore + external surface areas). Moreover, the BET surface area is in agreement with the accessible surface area calculated by chord length distribution $\left(\mathrm{S}_{\text {chord }}=2187\right.$ $\mathrm{m}^{2} / \mathrm{g}$ and $\left.\mathrm{S}_{\mathrm{BET}}=2108 \mathrm{~m}^{2} / \mathrm{g}\right),{ }^{18}$ provided the Rouquerol criterion is respected. Similar results have been obtained for a purely microporous $\operatorname{MOF}\left(\mathrm{S}_{\mathrm{chord}}=1979 \mathrm{~m}^{2} / \mathrm{g}\right.$ and $\left.\mathrm{S}_{\mathrm{BET}}=1958 \mathrm{~m}^{2} / \mathrm{g}\right) \cdot{ }^{18}$ it is therefore possible to use a BET calculation to determine the total surface area for materials containing microporosity.

The nitrogen isotherm at $77 \mathrm{~K}$ for FAU-Y has been recorded (Figure 1) and the BET surface area has been calculated taking into account the Rouquerol criterion. $\mathrm{S}_{\mathrm{BET}}$ for FAU-Y is $937 \mathrm{~m}^{2} / \mathrm{g}$. This value is close, but slightly lower than the accessible total surface area of FAU-Y calculated by computational chord length distribution $\left(\mathrm{S}_{\text {chord }}=1259 \mathrm{~m}^{2} / \mathrm{g}\right)$. The reported surface area of FAU-Y accessible to water molecules $(0.28 \mathrm{~nm}$ kinetic diameter $)$ is $1211 \mathrm{~m}^{2} / \mathrm{g}$, in accordance with the chord length distribution calculation of this study. ${ }^{21}$ The experimentally calculated $\mathrm{S}_{\mathrm{BET}}$ from the $\mathrm{N}_{2}$ isotherm is lower $\left(\mathrm{S}_{\mathrm{BET}}=937 \mathrm{~m}^{2} / \mathrm{g}\right)$, which can be explained by the use of the larger nitrogen molecule (0.364 nm kinetic diameter).

The BET surface area of FAU-Y was also determined from Ar isotherms at $87 \mathrm{~K}\left(\mathrm{~S}_{\mathrm{BET}}=\right.$ $821 \mathrm{~m}^{2} / \mathrm{g}$ ). This latter value is lower than the one obtained with $\mathrm{N}_{2}$. Ar has a similar kinetic diameter $(0.34 \mathrm{~nm})$ as $\mathrm{N}_{2},{ }^{22}$ but Ar is a globular nonpolar molecule that leads essentially to nonspecific interactions with all types of adsorbents. On the other hand, $\mathrm{N}_{2}$ has a particular ovoid shape and is quandrupolar, leading to specific interactions with hydroxylated surfaces. One hypothesis is that the ovoid shape of $\mathrm{N}_{2}$ allows nitrogen to partially enter the sodalite cages 
(window aperture approx. $0.28 \mathrm{~nm}$ ). Argon apparently only probes the supercages of FAU-Y (window aperture $0.74 \mathrm{~nm}$ ). Thus, the total micropore + external surface area of FAU-Y, as determined using the BET equation, is $937 \mathrm{~m}^{2} / \mathrm{g}$ and $821 \mathrm{~m}^{2} / \mathrm{g}$, respectively, when nitrogen and argon are used as adsorbates.

The second way to calculate the surface areas of porous materials is by the t-plot method, which plots the volume adsorbed as a function of the thickness $(\mathrm{t})$ of the adsorbed film. ${ }^{15,16}$ In order to obtain accurate t-plot curves, the choice of a reference isotherm with a surface chemistry similar to the studied material is essential. A non-porous silica (Aerosil-200) was used in this study as a reference isotherm over the partial pressure range $0.009<\mathrm{p} / \mathrm{p}_{0}<0.80$. For this range of pressure, the Aerosil 200 reference isotherm is in good agreement with the reference isotherms reported by Jaroniec et al. ${ }^{17}$ for the macroporous silica LiChrospher Si-1000, as well as other forms of standard adsorption isotherms. ${ }^{17}$ For our study, the Aerosil 200 reference isotherm was fit by parts to Eqs. 5-7 below. In comparison to the fitting procedure we reported in a previous publication, ${ }^{12}$ the present fitting results were in better agreement with the data presented by Jaroniec et al. ${ }^{17}$ These new fits were preferred for this study.

Equations 5-7 were used to transform $\mathrm{p} / \mathrm{p}_{0}$ into adsorbate layer thickness $\mathrm{t}$ :

$$
\begin{aligned}
& 0.009<\mathrm{p} / \mathrm{p}_{0}<0.12 \\
& \mathrm{t}=1.62973+76.4748\left(\mathrm{p} / \mathrm{p}_{0}\right)-2171.7914\left(\mathrm{p} / \mathrm{p}_{0}\right)^{2}+41734.77357\left(\mathrm{p} / \mathrm{p}_{0}\right)^{3}-465290.41181\left(\mathrm{p} / \mathrm{p}_{0}\right)^{4}+ \\
& 2.72432 .10^{6}\left(\mathrm{p} / \mathrm{p}_{0}\right)^{5}-6.43708 .10^{6}\left(\mathrm{p} / \mathrm{p}_{0}\right)^{6} \\
& 0.13<\mathrm{p} / \mathrm{p}_{0}<0.60
\end{aligned}
$$$$
\mathrm{t}=3.07721+5.64019\left(\mathrm{p} / \mathrm{p}_{0}\right)
$$ 


$$
\begin{aligned}
& 0.60<\mathrm{p} / \mathrm{p}_{0}<0.80 \\
& \mathrm{t}=4592.05803-38117.31548\left(\mathrm{p} / \mathrm{p}_{0}\right)+131602.19741\left(\mathrm{p} / \mathrm{p}_{0}\right)^{2}-241680.40239\left(\mathrm{p} / \mathrm{p}_{0}\right)^{3}+ \\
& 249079.8569\left(\mathrm{p} / \mathrm{p}_{0}\right)^{4}-136632.44762\left(\mathrm{p} / \mathrm{p}_{0}\right)^{5}+31182.4149\left(\mathrm{p} / \mathrm{p}_{0}\right)^{6}
\end{aligned}
$$

In order to obtain mesopore + external surface areas $\left(\mathrm{S}_{\text {mes+ext }}\right)$, the first linear t-plot fit was carried out at low $t$ with the equation:

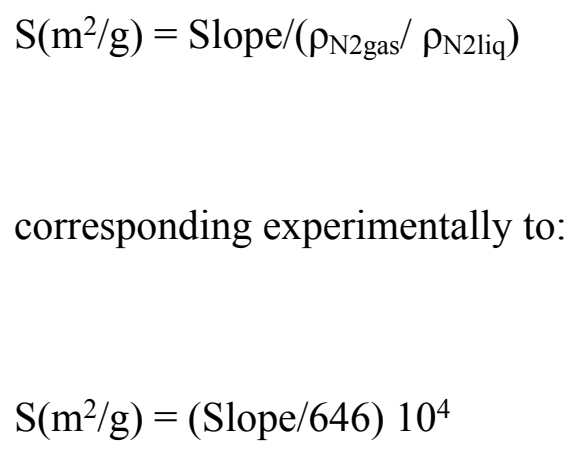

For external surface area determinations $\left(\mathrm{S}_{\mathrm{ext}}\right)$, the second linear fit of the t-plot (Figure 2) was performed at $\mathrm{t}$ below $0.92 \mathrm{~nm}$; that is, at pressures below $\mathrm{p} / \mathrm{p}_{0}=0.8$ where the domain of validity is observed for the t-plot curve obtained for Aerosil-200. $S_{\text {ext }}$ is calculated from the slope of the second linear fit at high t (Eq. 9).

The t-plot curve of MCM-41 shows two slopes (Figure 2), one before the condensation step due to mesopore filling and one after due to the adsorption on the external surface. The first slope represents the total surface area (mesopore + external surface), which is equivalent to BET the surface area for mesoporous materials, and the second slope at high pressure represents the external surface area. The mesopore surface area is calculated by difference between the total surface area and the external surface area. This can be done by two ways: the subtraction of the external surface area from the total surface area determined by (i) the BET equation or (ii) by the 
t-plot. The total pore volume (or mesopore volume in the case of MCM-41) is obtained when the experimental points start being inferior to the second linear fit of the t-plot at high pressure (high t, Figure 2). The external surface of MCM-41 is $143 \mathrm{~m} / \mathrm{g}$. A good correlation was found for MCM-41 between BET surface area $\left(843 \mathrm{~m}^{2} / \mathrm{g}\right)$ and mesopore + external surface area $\left(823 \mathrm{~m}^{2} / \mathrm{g}\right)$ determined by t-plot. The error in surface area determination is therefore $\pm 20 \mathrm{~m}^{2} / \mathrm{g}$ or around 2.5 $\%$ of the measured surface areas. The mesopore surface $\left(\mathrm{S}_{\mathrm{mes}}\right)$ of MCM-41 is then calculated by difference between $\mathrm{S}_{\mathrm{BET}}$ and $\mathrm{S}_{\text {ext }}\left(\mathrm{S}_{\mathrm{mes}}=700 \mathrm{~m}^{2} / \mathrm{g}\right)$ or between $\mathrm{S}_{\text {mes }+ \text { ext }}$ and $\mathrm{S}_{\text {ext }}\left(\mathrm{S}_{\mathrm{mes}}=680 \mathrm{~m}^{2} / \mathrm{g}\right)$. The total or mesopore volume of MCM-41 $(\mathrm{V}=0.66 \mathrm{~mL} / \mathrm{g})$ was taken as the point where the second slope of the t-plot departs from the experimental data (Figure 2).

In order to calculate the micropore surface area of FAU-Y, the external surface was first determined from the t-plot. The use of t-plot method for calculating the surface areas of microporous materials is subject to controversy ${ }^{13,15}$ and only external surface area calculation is recommended using the fit at high pressure (or high film thickness). ${ }^{15}$ T-plot of FAU-Y was determined (Figure 2) and $\mathrm{S}_{\mathrm{ext}}$ for FAU-Y was calculated $\left(85 \mathrm{~m}^{2} / \mathrm{g}\right)$. The micropore surface $\left(\mathrm{S}_{\mathrm{mic}}\right)$ of FAU-Y was then obtained by the difference between $\mathrm{S}_{\mathrm{BET}}$ and $\mathrm{S}_{\mathrm{ext}}$, which provided the value $\mathrm{S}_{\text {mic }}=852 \mathrm{~m}^{2} / \mathrm{g}$. The micropore volume of FAU-Y is difficult to assess by the t-plot method due to the compressibility of nitrogen in micropores, ${ }^{15}$ which, contrary to nitrogen in mesopores, leads to a non-constant nitrogen film thickness for a given pressure. The thickness of the film increases with decreasing micropore diameter. ${ }^{15}$ For materials containing micropores, the intercept of the first slope with the Y-axis usually is used to determine the micropore volume. But as shown by computational studies for pure microporous or micro-/mesoporous materials, t-plots underestimate micropore volumes ${ }^{15}$ and overestimate surface areas. ${ }^{13}$ The underestimation of micropore volume by t-plot method has been demonstrated experimentally for materials containing more than $10 \%$ micropore volume. ${ }^{12}$ For dealuminated FAU-Y, it is also difficult to 
measure exactly the micropore volume by t-plot as a few small mesopores $(2-4 \mathrm{~nm})$ arise in the material through dealumination, leading to additional volume. However the examination of the nitrogen adsorption at very low pressure expressed as $\log \left(\mathrm{p} / \mathrm{p}_{0}\right)$ (Figure $\mathrm{S} 1$ ) allows better identification of these small mesopores. The micropore volume $\left(\mathrm{V}_{\text {mic }}\right)$ of FAU-Y has been assumed to be filled completely at $\mathrm{p} / \mathrm{p}_{0}=0.1\left(\mathrm{~V}_{\text {mic }}=0.317 \mathrm{~mL} / \mathrm{g}\right)$. Thus, the intercept of the first slope of the t-plot with the Y-axis (Figure 2) for this purely micoporous material is misleading, because it corresponds instead to the underestimated value of $\left(\mathrm{V}_{\text {mic }}\right) \operatorname{tpt}=0.232 \mathrm{~mL} / \mathrm{g} .{ }^{12}$

By careful use of BET equations and t-plot methods, it was possible to assess the different surface areas for purely mesoporous materials and purely microporous materials. For mesoporous MCM-41, the two types of surface areas were $S_{\text {mes }}=680-700 \mathrm{~m}^{2} / \mathrm{g}$ and $\mathrm{S}_{\text {ext }}=143 \mathrm{~m}^{2} / \mathrm{g}$, whereas for FAU-Y, surface areas were $S_{\text {mic }}=852 \mathrm{~m}^{2} / \mathrm{g}$ and $\mathrm{S}_{\mathrm{ext}}=85 \mathrm{~m}^{2} / \mathrm{g}$.

\footnotetext{
Surface areas of mechanical mixtures of FAU-Y and MCM-41. As said previously, for micro/mesoporous materials, it has been shown by modeling that the t-plot method overestimates surface areas. ${ }^{13}$ To experimentally verify this conclusion, mechanical mixtures with different weighted portions of FAU-Y and MCM-41 with known micropore and mesopore surfaces, respectively, have been prepared by simple powders mixing without grinding and analyzed by nitrogen adsorption at $77 \mathrm{~K}$. The micropore and mesopore surface areas of the mixtures have been calculated independently by linear combination and compared to the results of the t-plot analysis (Figures 3, S3).
} 


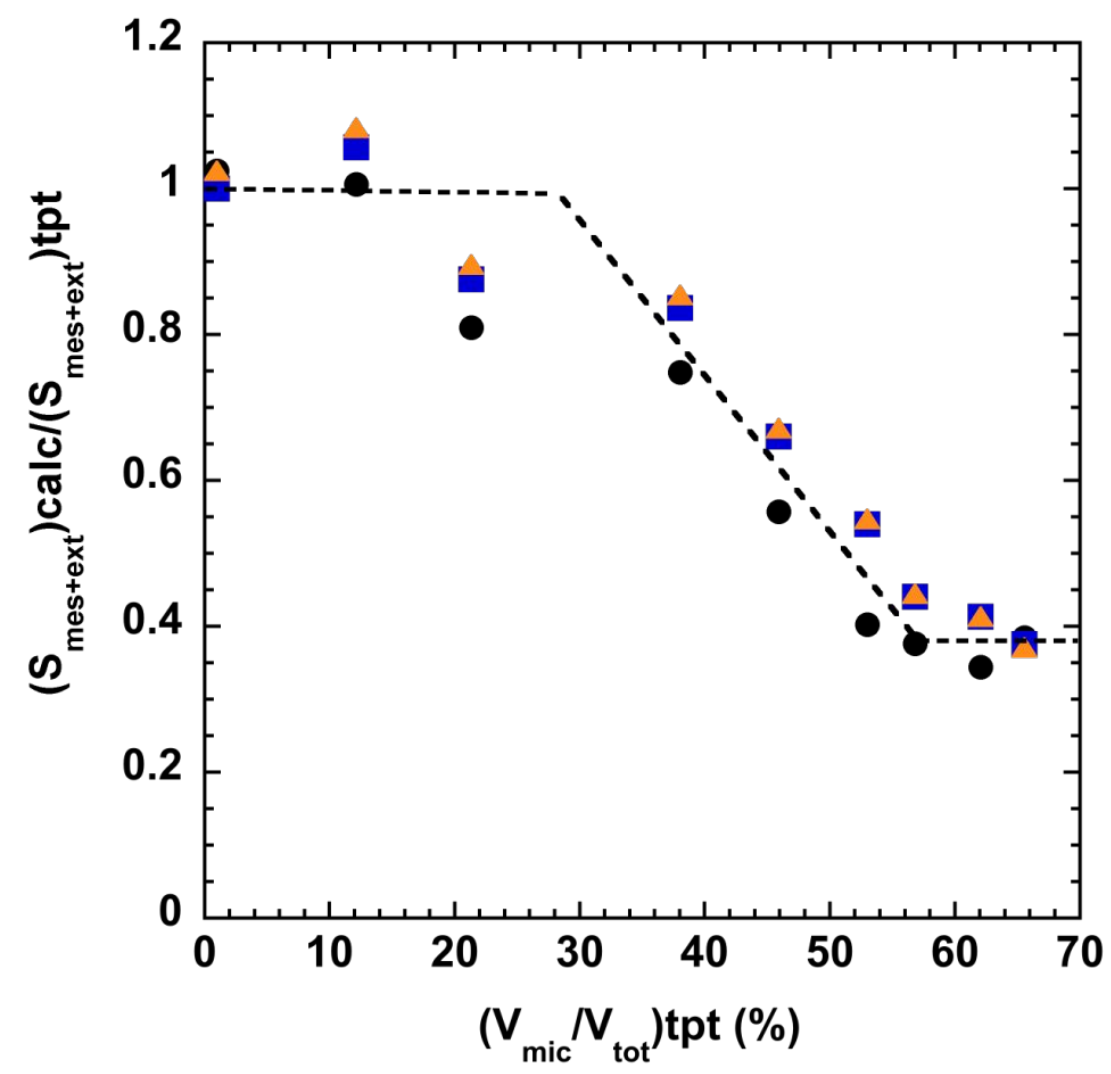

Figure 3. For mechanical mixtures of MCM-41 and FAU-Y, comparison of mesopore + external surface areas $\mathrm{S}_{\text {mes+ext }}$ determined by t-plot method $\left(\mathrm{S}_{\text {mes+ext }}\right)$ tpt and calculated by linear combination $\left(\mathrm{S}_{\text {mes+ext }}\right)$ calc as a function of the ratio of micropore volume to total pore volume determined by t-plot $\left(\mathrm{V}_{\text {mic }} / \mathrm{V}_{\text {tot }}\right)$ tpt. $\left(\mathrm{S}_{\text {mes+ext }}\right)$ calc were determined by 3 different ways: (1) by subtracting the weighted micropore surface of FAU-Y from $\mathrm{S}_{\mathrm{BET}}$ of the mixture (circles), (2) by adding the weighted $S_{\text {ext }}$ of the mixture to the weighted mesoporous surface $S_{\text {mes }}$ of MCM-41 calculated either from (i) $\mathrm{S}_{\mathrm{BET}}-\mathrm{S}_{\text {ext }}$ (triangles) or (ii) from $\mathrm{S}_{\text {mes }+ \text { ext }}-\mathrm{S}_{\text {ext }}$ (squares). The dashed line represents the fits of these points, which will be used to correct the $\left(\mathrm{S}_{\text {mes+ext }}\right)$ tpt of hierarchical microporous/mesoporous FAU-Y (FAUmes) materials. 
The external surface areas $\left(\mathrm{S}_{\text {ext }}\right)$ calc and the mesopore + external surface areas $\left(\mathrm{S}_{\text {mes+ext }}\right)$ calc of the mechanical mixtures of MCM-41 and FAU-Y were first calculated by weighted linear combination of the two types of surface areas. The "calculated" mesopore + external surface areas, $\left(\mathrm{S}_{\text {mes+ext }}\right)$ calc, were determined in three different ways: (1) by subtracting the weighted micropore surface of FAU-Y from the total surface $\mathrm{S}_{\mathrm{BET}}$ of the mixture (Figures 3, $\mathrm{S} 3$, circles), (2) by adding the weighted $\mathrm{S}_{\mathrm{ext}}$ of the mixture to the weighted mesoporous surface $\mathrm{S}_{\mathrm{mes}}$ of MCM-41 calculated either from (i) $\mathrm{S}_{\mathrm{BET}^{-}} \mathrm{S}_{\mathrm{ext}}$ (Figures 3, S3, triangles) or (ii) from $\mathrm{S}_{\text {mes }}+\mathrm{ext}^{-}$ $\mathrm{S}_{\text {ext }}$ (Figures 3, S3, squares). All of these approaches to calculate $\left(\mathrm{S}_{\text {mes+ext }}\right)$ calc for the mechanical mixtures are in good agreement (Figures 3, S3). The slightly lower values of $\left(\mathrm{S}_{\text {mes+ext }}\right)$ calc calculated by method 1 (Figures 3, S3, circles) are due to a small contribution of the mesopore surface in $\mathrm{S}_{\text {mic }}$ of FAU-Y due to the fact that FAU-Y is a dealuminated zeolite and contains a small volume $(0.036 \mathrm{~mL} / \mathrm{g})$ of small mesopores (diameter between $2-4 \mathrm{~nm})$.

For the mechanical mixtures of FAU-Y and MCM-41, the mesopore + external surface areas $\left(\mathrm{S}_{\text {mes+ext }}\right)$ tpt and micropore volumes $\left(\mathrm{V}_{\text {mic }}\right)$ tpt were then determined from the first linear fit of the t-plot at low $t$ (Figure S2). The linear fit of the first slope is in general in the range $0.01<$ $\mathrm{p} / \mathrm{p}_{0}<0.17$, corresponding to $0.2<\mathrm{t}<0.4 \mathrm{~nm}$, and contains the volumes and relative pressures at which all micropores are filled (ie. $\mathrm{p} / \mathrm{p}_{0}>0.10$, corresponding to $\mathrm{t}>0.36 \mathrm{~nm}$ ). The micropore volume $\left(\mathrm{V}_{\text {mic }}\right)$ tpt was obtained from the intercept of the first linear fit (low $\mathrm{t}$ ) with the $\mathrm{Y}$-axis and $\left(\mathrm{S}_{\text {mes+ext }}\right)$ tpt was calculated from the slope of this first fit (low $\left.t\right)$ with Eq. 9. The external surface area $\left(\mathrm{S}_{\text {ext }}\right)$ tpt was determined using Eq. 9 and the second linear fit of the t-plot (Figure $\mathrm{S} 2$ ) performed at high t below $0.92 \mathrm{~nm}$. The second linear fit corresponded to pressures below $\mathrm{p} / \mathrm{p}_{0}=$ 0.8 where the domain of validity was observed for the t-plot curve for the Aerosil-200 silica reference. 
The comparison between t-plot analysis for $\left(\mathrm{S}_{\text {ext }}\right)$ tpt and $\left(\mathrm{S}_{\text {mes+ext }}\right)$ tpt, and linear combination calculations for $\left(\mathrm{S}_{\text {ext }}\right)$ calc and $\left(\mathrm{S}_{\text {mes+ext }}\right)$ calc (Figures 3 and $\mathrm{S} 3$ ), reveals that the values for the external surface areas are equivalent. Although there is no overestimation of external surface areas by t-plot analysis (Figure $\mathrm{S} 3$ ), the $\mathrm{S}_{\text {mes+ext }}$ determined by t-plot $\left(\mathrm{S}_{\text {mes+ext }}\right)$ tpt overestimates the "calculated" value of $\mathrm{S}_{\text {mes+ext }}\left(\left(\mathrm{S}_{\text {mes+ext }}\right)\right.$ calc $)$ determined by linear combination for materials presenting a micropore surface area higher than $200 \mathrm{~m}^{2} / \mathrm{g}$ (Figures 3 and S3).

To better quantify the overestimation of $\left(\mathrm{S}_{\text {mes+ext }}\right)$ tpt by the t-plot method, the ratio $\left(\mathrm{S}_{\text {mes+ext }}\right)$ calc/( $\left.\mathrm{S}_{\text {mes+ext }}\right)$ tpt was represented as a function of the fraction of micropore volume $\left(\mathrm{V}_{\text {mid }} / \mathrm{V}_{\text {tot }}\right)$ contained in the mechanical mixtures as determined by t-plot $\left(\left(\mathrm{V}_{\text {mid }} / \mathrm{V}_{\text {tot }}\right)\right.$ tpt) (Figure 3). As explained previously, the total pore volume $\left(\mathrm{V}_{\text {tot }}\right)$ was taken from the t-plot (Figure $\mathrm{S} 2$ ) when the second fit (high $\mathrm{t}$ ) deviates from the experimental points as previously demonstrated by modeling. ${ }^{15}$ The micropore volume is given by the intercept of the first fit of the t-plot (low $t$ ) with the $\mathrm{Y}$-axis (Figure $\mathrm{S} 2)$. The highest ratio $\left(\mathrm{V}_{\text {mic }} / \mathrm{V}_{\text {tot }}\right)$ tpt observed by $\mathrm{t}$-plot is for pure FAU-Y and corresponds to $\left(\mathrm{V}_{\text {mic }} / \mathrm{V}_{\text {tot }}\right)$ tpt $=70 \%$, not $100 \%$ due to the underestimation of micropore volume. ${ }^{12}$ As a result, this graph (Figure 3) shows that the t-plot method gives accurate results for $\mathrm{S}_{\text {mes+ext }}\left(\left(\mathrm{S}_{\text {mes+ext }}\right)\right.$ calc $=\left(\mathrm{S}_{\text {mes+ext }}\right)$ tpt $)$ for materials containing less than $30 \%$ of micropore volume $\left(0<\left(\mathrm{V}_{\text {mic }} / \mathrm{V}_{\text {tot }}\right)\right.$ tpt $\left.<30 \%\right)$. For larger amounts of micropore volume, $\mathrm{S}_{\text {mes+ext }}$ is overestimated by the t-plot method, and the overestimation increases linearly with increase in the micropore volume until a maximum is reached $\left(\mathrm{V}_{\text {mic }} / \mathrm{V}_{\text {tot }}\right)$ tpt $>55 \%$ (Figure 3$)$.

The following equations (Eq. $10-12$ ) have are provided to correct $\left(\mathrm{S}_{\text {mes+ext }}\right)$ tpt determined by t-plot method for microporous/mesoporous materials:

$$
\begin{array}{ll}
\left(\mathrm{V}_{\text {mic }} / \mathrm{V}_{\text {tot }}\right) \operatorname{tpt}<30 \%: & \left(\mathrm{S}_{\text {mes+ext }}\right) \text { calc } /\left(\mathrm{S}_{\text {mes }+ \text { ext }}\right) \mathrm{tpt}=1 \\
30<\left(\mathrm{V}_{\text {mic }} / \mathrm{V}_{\text {tot }}\right) \mathrm{tpt}<55 \%: & \left(\mathrm{S}_{\text {mes+ext }}\right) \text { calc } /\left(\mathrm{S}_{\text {mes+ext }}\right) \mathrm{tpt}=1.6-0.02138\left(\mathrm{~V}_{\text {mic }} / \mathrm{V}_{\text {tot }}\right)_{\text {tpt }}
\end{array}
$$


$\left(\mathrm{V}_{\text {mic }} / \mathrm{V}_{\text {tot }}\right)$ tpt $>55 \%: \quad\left(\mathrm{S}_{\text {mestext }}\right)$ calc $/\left(\mathrm{S}_{\text {mes+ext }}\right) \mathrm{tpt}=0.38$

with $\left(\mathrm{V}_{\text {mic }} / \mathrm{V}_{\text {tot }}\right)$ tpt expressed in $\%$.

Surface areas of a family of hierarchical mesoporous FAU-Y. In order to improve transport properties of zeolite crystals mesopores can be created. ${ }^{1-10}$ In 2005 , an attractive procedure was proposed consisting of the transformation of a silica-rich FAU-Y into mesoporous FAU-Y by a post-treatment in an alkaline solution containing alkyltrimethylammonium bromide surfactants (CnTAB). This created homogeneous ordered mesopores as in MCM-41 materials inside the FAU-Y crystals. ${ }^{8-10}$ In the present study, mesoporous FAU-Y materials (named FAUmes) were synthesized using $\mathrm{C} 18 \mathrm{TAB}$ surfactant with different $\mathrm{NaOH} / \mathrm{Si}$ ratio $(0.025<\mathrm{NaOH} / \mathrm{Si}<0.25)$. Their nitrogen isotherms at $77 \mathrm{~K}$ have been performed (Figure 1) and their BET surface areas and t-plots have been analyzed (Figures 2 and S4) to calculate their external, micropore and mesopores surface areas taking into account the corrections of $\left(\mathrm{S}_{\text {mes+ext }}\right) \operatorname{tpt}($ Eq. $10-12)$ provided by the results for mechanical mixtures of FAU-Y and MCM-41.

$\left(\mathrm{S}_{\text {mes+ext }}\right)$ tpt surface areas were calculated from the slope (Eq. 9) of the first linear fit of the t-plot. The linear fit of the first slope was in general in the range $0.01<\mathrm{p} / \mathrm{p}_{0}<0.17$ (corresponding to $0.2<\mathrm{t}<0.4 \mathrm{~nm}$ ) and contains the volumes and relative pressures at which all micropores are filled (ie. $\mathrm{p} / \mathrm{p}_{0}>0.10$, corresponding to $\mathrm{t}>0.36 \mathrm{~nm}$ ) (Figures 2, $\mathrm{S} 4$ ). $\left(\mathrm{V}_{\text {mic }}\right) \mathrm{tpt}$ micropore volumes were measured at the intercept of the $\mathrm{Y}$-axis with this first linear fit. $\left(\mathrm{S}_{\text {ext }}\right) \mathrm{tpt}$ surface areas were calculated from the slope (Eq. 9) of the second linear fit. The linear fit of the second slope was in general in the range $0.65<\mathrm{p} / \mathrm{p}_{0}<0.82$ (corresponding to $0.7<\mathrm{t}<0.9 \mathrm{~nm}$ ) and contains the volumes and relative pressures below $\mathrm{p} / \mathrm{p}_{0}<0.80$ (corresponding to $\mathrm{t}<0.92$ $\mathrm{nm}$ ), where the domain of validity was observed for the t-plot curve for the Aerosil-200 silica 
reference. The total pore volumes $\left(\mathrm{V}_{\text {tot }}\right)$ tpt were taken from the second linear fit of the t-plot where it leaves the experimental data points (Table 1). The above equations (Eq. 10-12) have been applied to $\left(\mathrm{S}_{\text {mes+ext }}\right)$ tpt to obtain corrected values named $\left(\mathrm{S}_{\text {mestext }}\right)$ cor (Table 1$)$.

The transformation of FAU-Y into FAUmes depends of the $\mathrm{NaOH} / \mathrm{Si}$ ratio used in the synthesis. The step at $\mathrm{p} / \mathrm{p}_{0}$ around 0.4 in the nitrogen isotherms (Figure 1) is characteristic of the formation of ordered mesopores of ca. $4 \mathrm{~nm}$ in the materials due to micelle-templating. This step is observed for $0.0625<\mathrm{NaOH} / \mathrm{Si}<0.25$ revealing the transformation of FAU-Y into FAUmes for this range of $\mathrm{NaOH} / \mathrm{Si}$ ratio. Too low $\mathrm{NaOH} / \mathrm{Si}$ ratio, such as $\mathrm{NaOH} / \mathrm{Si}=0.05$, does not allow for the transformation into FAUmes. External surface areas for FAU-Y and untransformed FAU$\mathrm{Y}(0<\mathrm{NaOH} / \mathrm{Si}<0.05)$ were around $100 \mathrm{~m}^{2} / \mathrm{g}$ and decrease to ca. $30 \mathrm{~m}^{2} / \mathrm{g}$ for FAUmes $(0.0625$ $<\mathrm{NaOH} / \mathrm{Si}<0.25$ ). Initial FAU-Y particles are built by an aggregation of crystals of different size and morphology around $1 \mu \mathrm{m}$ diameter forming aggregates of ca. $10 \mu \mathrm{m}$. The transformation of FAU-Y into FAUmes occurs also in between the crystal aggregates and on the outer surface the crystals leading to a slight increase of particles diameter of ca. $30 \mu \mathrm{m}^{23}$ and, therefore, to a decrease of external surface areas by a factor 3 to 4 . Mesopore surface areas $\left(\mathrm{S}_{\mathrm{mes}}\right)$ cor have been calculated by difference between corrected $\mathrm{S}_{\text {mestext }}$ surface areas $\left(\mathrm{S}_{\text {mestext }}\right)$ cor and external surface areas $\left(\mathrm{S}_{\text {ext }}\right)$ tpt: $\left(\mathrm{S}_{\mathrm{mes}}\right)$ cor $=\left(\mathrm{S}_{\mathrm{mes}+\mathrm{ext}}\right) \operatorname{cor}-\left(\mathrm{S}_{\text {ext }}\right)$ tpt $($ Table 1).

To assess micropore surface areas of FAUmes materials by subtracting $\left(\mathrm{S}_{\text {mestext }}\right)$ cor from the total surface area, the total surface areas of the materials have been calculated by BET equation $\left(\mathrm{S}_{\mathrm{BET}}\right)$ using the Rouquerol criterion ${ }^{11}$ (Figures $\left.4, \mathrm{~S} 5\right)$ to determine the highest $\mathrm{p} / \mathrm{p}_{0}$ pressure to use in the fit of the BET equation. 


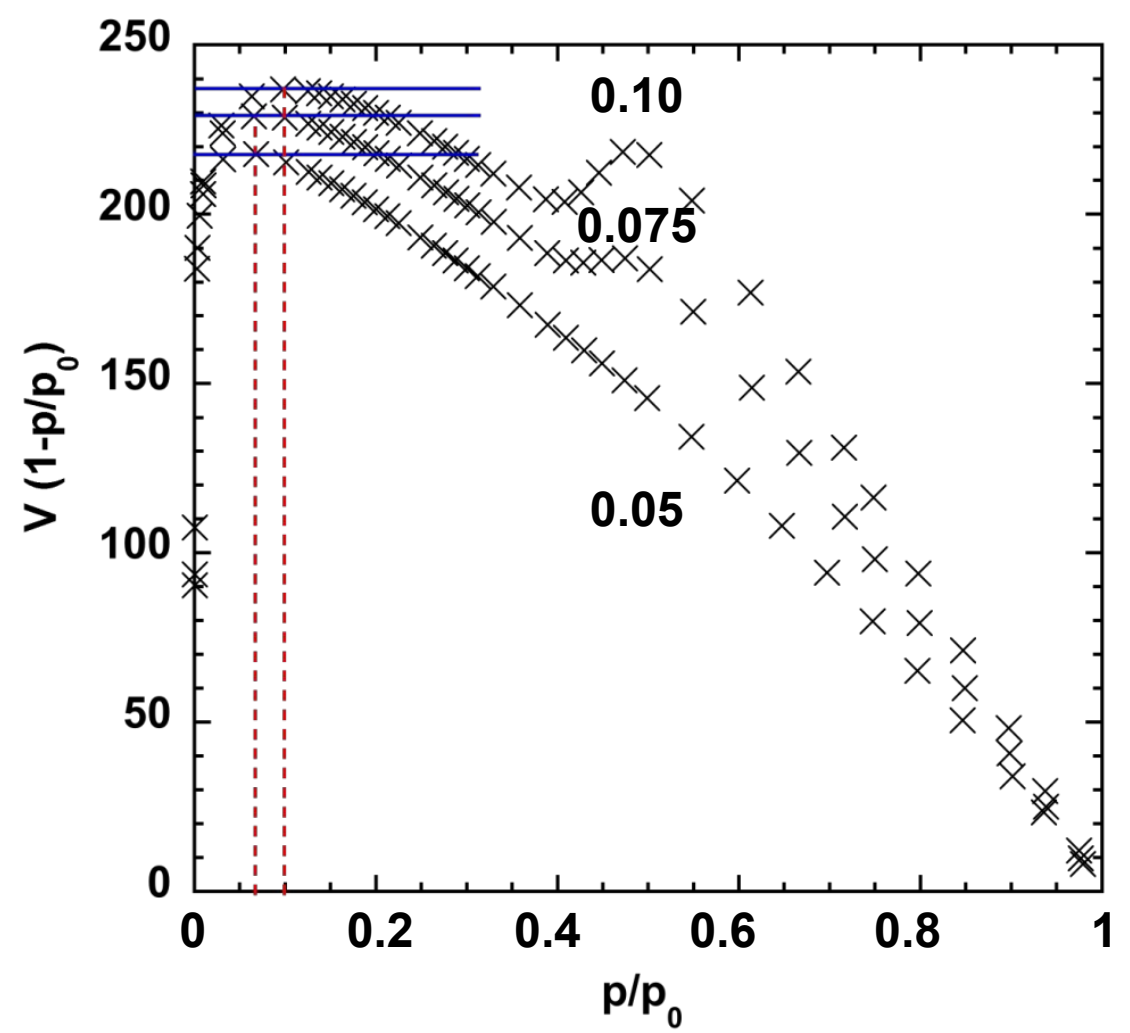

Figure 4. Examples of Rouquerol plots of hierarchical microporous/mesoporous FAUmes synthesized from H-FAU-Y with C18TAB surfactant and different $\mathrm{NaOH} / \mathrm{Si}$ ratio $(\mathrm{NaOH} / \mathrm{Si}=$ $0.05,0.075,0.10$, indicated on each curves) to determine the highest $\mathrm{p} / \mathrm{p}_{0}$ pressure (corresponding to the crossing between red and blue lines) to use in the fit of the BET equation to calculate $\mathrm{S}_{\mathrm{BET}}$.

The total surface areas $\left(\mathrm{S}_{\mathrm{BET}}\right)$ is constant $\left(937 \mathrm{~m}^{2} / \mathrm{g}\right)$ for FAU-Y and for untransformed FAU-Y $(0<\mathrm{NaOH} / \mathrm{Si}<0.05)$, whereas $\mathrm{S}_{\mathrm{BET}}$ increases from 894 to $956 \mathrm{~m}^{2} / \mathrm{g}$ with increase of $\mathrm{NaOH} / \mathrm{Si}$ ratio for $0.075<\mathrm{NaOH} / \mathrm{Si}<0.125$ and then remains constant $\left(949 \mathrm{~m}^{2} / \mathrm{g}\right)$ for higher values of $\mathrm{NaOH} / \mathrm{Si}(0.125<\mathrm{NaOH} / \mathrm{Si}<0.25)($ Table 1$)$. The $\mathrm{S}_{\mathrm{BET}}$ surface areas calculated from nitrogen adsorption isotherms are sensitive to the surface chemistry of the materials, as the cross- 
section of $\mathrm{N}_{2}$ molecules can vary from $0.135 \mathrm{~nm}^{2}$ for a hydrophilic surface to $0.162 \mathrm{~nm}^{2}$ for a hydrophobic surface depending on the orientation of the molecule with the surface. ${ }^{19}$ The latter cross-section $\left(0.162 \mathrm{~nm}^{2}\right)$ is typically used in $\mathrm{S}_{\mathrm{BET}}$ calculation (Eq. 3,4).

In order to evaluate surface hydrophilicity, $\mathrm{S}_{\mathrm{BET}}$ surface areas were also assessed from $\mathrm{Ar}$ isotherms at $87 \mathrm{~K}$. The $\mathrm{S}_{\mathrm{BET}}$ calculated from the Ar isotherms were constant $\left(780 \mathrm{~m}^{2} / \mathrm{g}\right)$ except for untransformed FAU-Y materials $(0<\mathrm{NaOH} / \mathrm{Si}<0.05)$, which show the highest surface areas $\left(820 \mathrm{~m}^{2} / \mathrm{g}\right)$. To analyze the micropore + mesopore surface areas of the materials, the external surface areas $\left(\mathrm{S}_{\mathrm{ext}}\right)$ tpt were subtracted from the total surface areas $\left(\mathrm{S}_{\mathrm{BET}}\right)$ (Figure $\left.\mathrm{S} 6\right)$. The resulting micropore + mesopore surface areas for FAUmes materials determined from $\mathrm{Ar}$ isotherms were constant $\left(740 \mathrm{~m}^{2} / \mathrm{g}\right)$ for all $\mathrm{NaOH} / \mathrm{Si}$ ratio $(0<\mathrm{NaOH} / \mathrm{Si}<0.25)$, whereas the micropore + mesopore surface areas determined from nitrogen isotherms increase from 855 to $930 \mathrm{~m}^{2} / \mathrm{g}$ with increase in $\mathrm{NaOH} / \mathrm{Si}$ ratio in the range $0<\mathrm{NaOH} / \mathrm{Si}<0.125$ and then remain constant $\left(920 \mathrm{~m}^{2} / \mathrm{g}\right)$ for higher $\mathrm{NaOH} / \mathrm{Si}$ ratio $(0.125<\mathrm{NaOH} / \mathrm{Si}<0.25)$ (Figure $\left.\mathrm{S} 6\right)$.

The Ar isotherm results show that the progressive increase of micropore + mesopore surface area observed from $\mathrm{N}_{2}$ isotherms for the $0.05<\mathrm{NaOH} / \mathrm{Si}<0.125$ samples is due to a change of the orientation of the nitrogen molecules on the surface. The progressive increase in the hydrophilic character of the surface during the transformation into FAUmes arises from an increase in the density of silanol groups on the surface of the materials. ${ }^{1}$ FAU-Y and untransformed FAU-Y $(0<\mathrm{NaOH} / \mathrm{Si}<0.05)$ feature a hydrophobic surface as silanol groups are isolated and nitrogen molecules are lying on the surface giving a cross-section of $0.162 \mathrm{~nm}^{2}$. By increasing the $\mathrm{NaOH} / \mathrm{Si}$ ratio, silanol groups are formed ${ }^{1}$ and the interactions between silanol groups increase, increasing the hydrophilic character of the surface of FAUmes materials. $\mathrm{N}_{2}$ molecules are progressively oriented more perpendicularly to the surface and $\mathrm{N}_{2}$ molecules crosssection decreases. The cross-section value of nitrogen molecules for the highest hydrophilic 
character of the materials (FAUmes synthesized with $0.125<\mathrm{NaOH} / \mathrm{Si}<0.25$ ) corresponding to $920 \mathrm{~m}^{2} / \mathrm{g}$ instead of $855 \mathrm{~m}^{2} / \mathrm{g}$ can be estimated by assuming a constant BET surface area for all materials (as demonstrated by Ar adsorption). The $\mathrm{N}_{2}$ molecule cross-section would become $0.1404 \mathrm{~nm}^{2}$ instead of $0.162 \mathrm{~nm}^{2}$.

Corrections of $\mathrm{S}_{\mathrm{BET}}$ determined by nitrogen have been done with this new nitrogen crosssection for FAUmes synthesized with $0.075<\mathrm{NaOH} / \mathrm{Si}<0.25$ and called $\mathrm{S}_{\mathrm{BET}} *$ (Table 1). The micropore, mesopore and micropore + mesopore surface areas have been calculated for all materials using either $\mathrm{S}_{\mathrm{BET}}$ or $\mathrm{S}_{\mathrm{BET}}$ * taking also into account corrections of $\mathrm{S}_{\mathrm{mes}+\mathrm{ext}}$ determined by t-plot method $\left(\mathrm{S}_{\text {mestext }}\right)$ cor. $\mathrm{S}_{\mathrm{BET}}$ was used for materials synthesized with $0<\mathrm{NaOH} / \mathrm{Si}<0.0625$ and $\mathrm{S}_{\mathrm{BET}} *$ for $0.075<\mathrm{NaOH} / \mathrm{Si}<0.25$. The micropore surface areas have been calculated from the difference of total surface areas $\left(\mathrm{S}_{\mathrm{BET}}\right.$ or $\left.\mathrm{S}_{\mathrm{BET}}{ }^{*}\right)$ with $\left(\mathrm{S}_{\text {mestext }}\right)$ cor and named $\left(\mathrm{S}_{\mathrm{mic}}\right)$ cor or $\left(\mathrm{S}_{\text {mic }}{ }^{*}\right)$ cor, respectively (Table 1$)$. The mesopore surface areas were calculated by subtracting $\left(\mathrm{S}_{\mathrm{ext}}\right)$ tpt from $\left(\mathrm{S}_{\text {mestext }}\right)$ cor and named $\left(\mathrm{S}_{\mathrm{mes}}\right)$ cor $($ Table 1$)$. The micropore + mesopore surface areas have been calculated by difference of $\mathrm{S}_{\mathrm{BET}}$ or $\mathrm{S}_{\mathrm{BET}} *$ with external surface areas $\left(\mathrm{S}_{\mathrm{ext}}\right)$ tpt (Figure 5). 


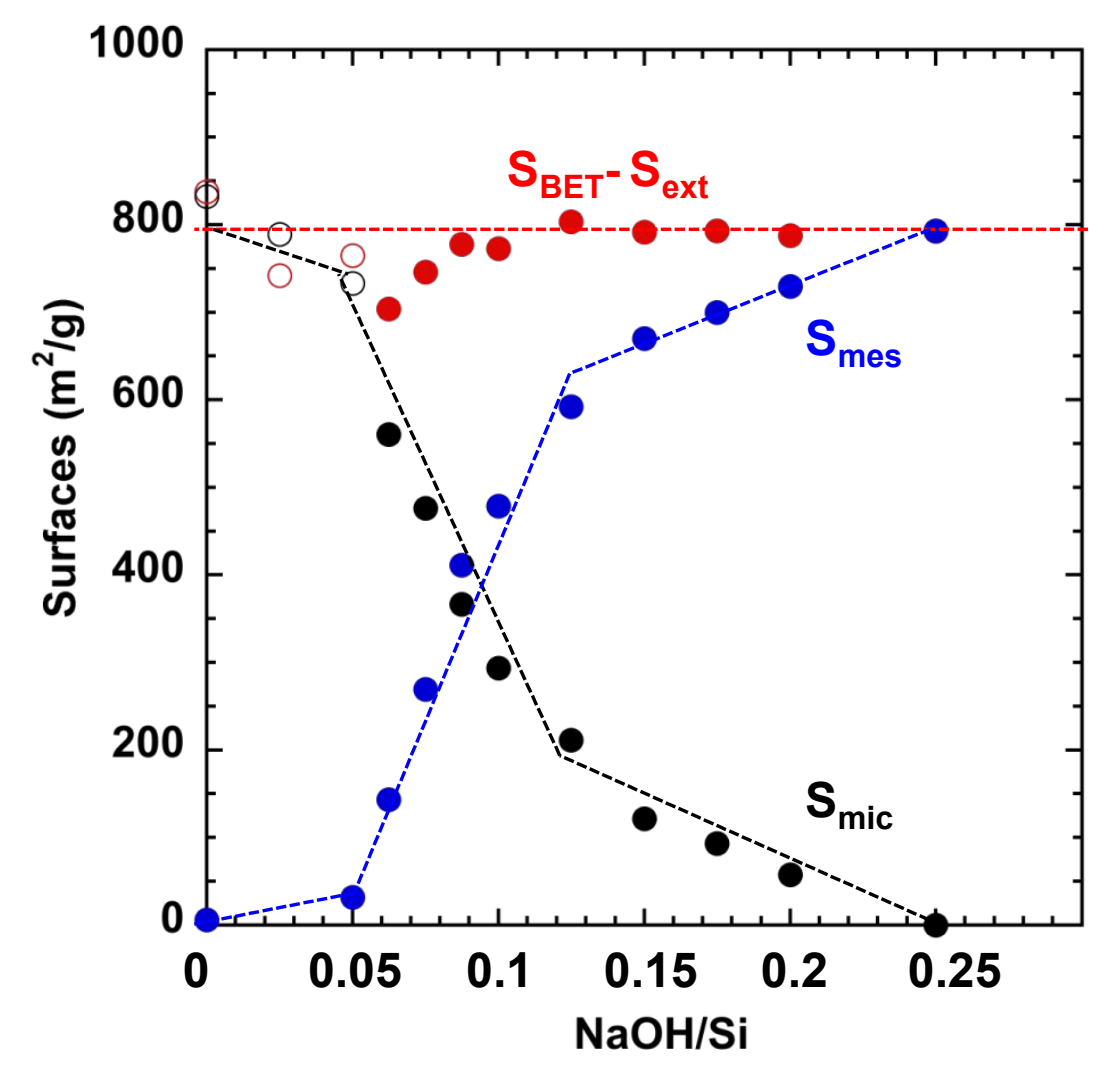

Figure 5. Micropore $\left(\mathrm{S}_{\mathrm{mic}}\right)$ cor and mesopore $\left(\mathrm{S}_{\mathrm{mes}}\right)$ cor surface areas of hierarchical microporous/mesoporous FAU-Y (FAUmes) synthesized from H-FAU-Y with C18TAB surfactant and different $\mathrm{NaOH} / \mathrm{Si}$ ratio determined by t-plot analysis and corrections (Eq. 10-12). The micropore + mesopore surface areas of FAUmes $\left(\mathrm{S}_{\mathrm{BET}}-\mathrm{S}_{\mathrm{ext}}\right)$ has been determined by subtracted the external surface $\left(\mathrm{S}_{\mathrm{ext}}\right)$ tpt from $\mathrm{S}_{\mathrm{BET}}$ or $\mathrm{S}_{\mathrm{BET}} *$. $\mathrm{S}_{\mathrm{BET}}$ or $\mathrm{S}_{\mathrm{BET}} *$ was calculated with nitrogen cross-section of 0.162 or $0.1404 \mathrm{~nm}^{2}$ for FAUmes synthesized with $\mathrm{NaOH} / \mathrm{Si}=0-$ 0.0625 and $0.075-0.25$, respectively.

Surface area calculations for FAUmes materials show that the micropore surface areas $\left(\mathrm{S}_{\text {mic }}\right)$ cor decreases and the mesopore surface areas $\left(\mathrm{S}_{\mathrm{mes}}\right)$ cor increases with the increase of the 
$\mathrm{NaOH} / \mathrm{Si}$ ratio in the synthesis, while the micropore +mesopore surface areas remain constant (Figure 5). The transformation of FAU-Y into mesoporous FAU-Y occurs with the same surface area (micropore + mesopore surface areas) as FAU-Y $\left(937 \mathrm{~m}^{2} / \mathrm{g}\right)$. The microporous surface is replaced by a mesoporous structure of similar surface area $\left(954 \mathrm{~m}^{2} / \mathrm{g}\right.$ for FAUmes synthesized with $\mathrm{NaOH} / \mathrm{Si}=0.25$ with almost no microporosity). The transformation of FAU-Y into FAUmes is accompanied by an increase of the surface hydrophilicity. A FAUmes material featuring an equivalent micropore and mesopore surface area should be obtained with $\mathrm{NaOH} / \mathrm{Si}=$ 0.095 in the synthesis (Figure 5) and would feature an intermediate hydrophobicity/hydrophilicity in between FAU-Y and amorphous ordered mesoporous material as the one synthesized with $\mathrm{NaOH} / \mathrm{Si}=0.25($ Figure $\mathrm{S} 6)$.

\section{CONCLUSIONS}

A methodology to decouple total, external, mesopore and micropore surface areas for micro/mesoporous materials using the t-plot method and BET equation has been provided. $\mathrm{S}_{\mathrm{BET}}$ can be used to evaluate the total surface areas (microporous + mesoporous + external surface) of micro/mesoporous materials if the Rouquerol criterion is well respected. By using mechanical mixtures of FAU-Y and MCM-41 materials of experimentally determined micropore and mesopore surface areas, respectively, it was shown that mesoporous + external surface areas $\left(\mathrm{S}_{\text {mes+ext }}\right)$ determined by the t-plot are overestimated for materials containing more than $30 \%$ of micropore volume. Corrections for the overestimation of $\mathrm{S}_{\text {mes+ext }}$ have been provided. This methodology has been applied to decouple the micropore and the mesopore surface areas of a family of hierarchical micro-/mesoporous FAU-Y (FAUmes) synthesized from FAU-Y in presence of 
octadecyltrimethyl ammonium bromide and different $\mathrm{NaOH} / \mathrm{Si}$ ratios $(0<\mathrm{NaOH} / \mathrm{Si}<0.25)$. These characterizations of FAUmes show that the micropore surface area decreases and the mesopore surface area increases with the increase of $\mathrm{NaOH} / \mathrm{Si}$ ratio, while the micropore + mesopore surface area remains constant. An equivalent micropore surface area and mesopore surface area is expected for a FAUmes material synthesized with $\mathrm{NaOH} / \mathrm{Si}=0.095$. Comparisons of BET surface areas of FAUmes materials determined by $\mathrm{N}_{2}$ isotherms at $77 \mathrm{~K}$ and Ar isotherms at $87 \mathrm{~K}$ show that FAU-Y features a hydrophobic character and that by transforming FAU-Y into FAUmes the hydrophilicity of the surface increases with the increase of $\mathrm{NaOH} / \mathrm{Si}$, especially in between $0.065<\mathrm{NaOH} / \mathrm{Si}<0.11$, and then the surface remains hydrophilic for $0.125<\mathrm{NaOH} / \mathrm{Si}$ $<0.25$. The combination of t-plot method and BET equation is a powerful tool to evaluate independently the micropore and mesopore surface areas of micro-/mesoporous materials. Equations given in this study to correct the overestimation of mesopore surface areas determined by t-plot method for hierarchical microporous/mesoporous materials apply to nitrogen isotherms

at $77 \mathrm{~K}$. However, these are not suitable for Ar adsorption at $87 \mathrm{~K}$. Similar work will be performed to assess the micropore and mesopore surface areas from Ar isotherms in a future work.

\section{ACKNOWLEDGMENTS}

The authors thank TOTAL S. A. for financial support, F. Fajula for fruitful discussions, J-M. Goupil for discussions on t-plot standard isotherms comparison, M. Thommes for Ar adsorption isotherms at $87 \mathrm{~K}$ measurements and J. Rodriguez for low pressure nitrogen isotherms at $77 \mathrm{~K}$. We thank Professor Thomas J. Pinnavaia for help in editing the text to improve English grammar. A. Galarneau would like to dedicate this article to Pr. Kenneth Sing and Pr. Françoise Rouquerol, 
two important researchers in fundamental adsorption and the characterization of porous solids, who passed away recently (2016 and 2017, respectively).

Supporting informations: Additional t-plots of mechanical mixture of FAU-Y and MCM-41 and of mesoporous FAU-y (FAUmes). Additional Rouquerol plots. Comparison of mesopore + external surface areas of the mechanical mixtures of FAU-Y and MCM-41 as a function of micropore surface area. Equations for the relationship between thickness $\mathrm{t}$ and $\mathrm{p} / \mathrm{p}_{0}$ for the analysis of the low pressure part $\left(\mathrm{p} / \mathrm{p}_{0}<0.01\right)$ of the isotherms. 
Table 1. Textural features of hierarchical mesoporous FAU-Y (FAUmes) synthesized with $\mathrm{C} 18 \mathrm{TAB}$ surfactant and different $\mathrm{NaOH} / \mathrm{Si}$ ratios produced from nitrogen sorption isotherms at $77 \mathrm{~K}$. Total, mesopore and micropore volumes and surface areas have been calculated using BET equation and t-plot analysis (tpt) and corrected values of t-plot (cor). For t-plot analysis Aerosil 200 was used as reference isotherm.

\begin{tabular}{|c|c|c|c|c|c|c|c|c|c|c|c|c|}
\hline \multirow[t]{3}{*}{$\mathrm{NaOH} / \mathrm{Si}$} & $\overline{\mathrm{S}_{\mathrm{BET}}}$ & $\mathrm{S}_{\mathrm{BET} *}$ & $\mathrm{~V}_{\text {tot }}$ & $\mathrm{V}_{\text {mic }}$ & $\mathrm{S}_{\text {mes+ext }}$ & $\mathrm{V}_{\text {mic }}$ & $\overline{V_{\text {mes }}}$ & $\mathrm{S}_{\text {mes+ext }}$ & $\mathrm{S}_{\mathrm{mes}}$ & $\overline{\mathrm{S}_{\mathrm{mic}}}$ & $\mathrm{S}_{\mathrm{mic}}{ }^{*}$ & $\mathrm{~S}_{\mathrm{ext}}$ \\
\hline & & & tpt & tpt & tpt & cor & cor & cor & cor & cor & cor & tpt \\
\hline & $\mathrm{m}^{2} / \mathrm{g}$ & $\mathrm{m}^{2} / \mathrm{g}$ & $\mathrm{mL} / \mathrm{g}$ & $\mathrm{mL} / \mathrm{g}$ & $\mathrm{m}^{2} / \mathrm{g}$ & $\mathrm{mL} / \mathrm{g}$ & $\mathrm{mL} / \mathrm{g}$ & $\mathrm{m}^{2} / \mathrm{g}$ & $\mathrm{m}^{2} / \mathrm{g}$ & $\mathrm{m}^{2} / \mathrm{g}$ & $\mathrm{m}^{2} / \mathrm{g}$ & $\mathrm{m}^{2} / \mathrm{g}$ \\
\hline 0 & 937 & & 0.431 & 0.265 & 276 & 0.371 & 0.060 & 105 & 6 & 832 & & 99 \\
\hline 0.025 & 868 & & 0.383 & 0.258 & 208 & 0.361 & 0.022 & 79 & -47 & 789 & & 126 \\
\hline 0.05 & 861 & & 0.437 & 0.233 & 278 & 0.326 & 0.111 & 128 & 32 & 733 & & 96 \\
\hline 0.0625 & 885 & & 0.479 & 0.222 & 339 & 0.311 & 0.168 & 206 & 143 & 679 & & 63 \\
\hline 0.075 & 894 & 775 & 0.534 & 0.209 & 391 & 0.280 & 0.254 & 298 & 269 & 596 & 476 & 29 \\
\hline 0.0875 & 923 & 780 & 0.592 & 0.190 & 474 & 0.242 & 0.350 & 433 & 411 & 490 & 366 & 22 \\
\hline 0.10 & 926 & 802 & 0.634 & 0.180 & 509 & 0.222 & 0.411 & 509 & 479 & 417 & 293 & 30 \\
\hline 0.125 & 957 & 829 & 0.714 & 0.149 & 618 & 0.170 & 0.544 & 618 & 592 & 339 & 211 & 26 \\
\hline 0.15 & 949 & 822 & 0.766 & 0.116 & 701 & 0.122 & 0.644 & 701 & 670 & 248 & 121 & 31 \\
\hline 0.175 & 960 & 832 & 0.782 & 0.102 & 739 & 0.103 & 0.678 & 739 & 700 & 221 & 93 & 39 \\
\hline 0.20 & 956 & 828 & 0.790 & 0.085 & 771 & 0.085 & 0.705 & 771 & 730 & 185 & 58 & 41 \\
\hline 0.25 & 954 & 827 & 0.811 & 0.057 & 827 & 0.057 & 0.754 & 827 & 793 & 127 & 0 & 34 \\
\hline
\end{tabular}

*with $\mathrm{S}_{\mathrm{BET}}$ calculated with nitrogen surface $0.1404 \mathrm{~nm}^{2}$ for $0.075<\mathrm{NaOH}<0.25$ 


\section{REFERENCES}

(1) Kazakov, M. O.; Nadeina, K. A.; Danilova, I. G.; Dik, P. P.; Klimov, O. V.; Pereyna, V. Yu.; Gerasimov, E. Yu.; Dobryakova, I. V.; Knyazeva, E. E.; Ivanova, I. I.; Noskov, A. S. Hydrocracking of Vacuum Gas Oil over $\mathrm{NiMo} / \gamma-\mathrm{Al}_{2} \mathrm{O}_{3}$ : Effect of Mesoporosity Introduced by Zeolite Y Recrystallization, Catal. Today, 2017, in press https://doi.org/10.1016/j.cattod.2017.08.048

(2) Bellussi, G. ; Millini, R. ; Pollesel, P.; Perego, C. Zeolite science and technology at Eni, New J. Chem., 2016, 40 (5), 4061-4077.

(3) Serrano, D. P.; Escola, J. M.; Sanz, R.; Garcia, R. A.; Peral, A.; Moreno, I.; Linares, M. Hierarchical ZSM-5 zeolite with uniform mesopores and improved catalytic properties, New J. Chem., 2016, 40 (5), 4206-4216.

(4) Ivanova, I. I.; Knyazeva, E. E. Micro-mesoporous materials obtained by zeolite recrystallization: synthesis, characterization and catalytic applications, Chem. Soc. Rev., 2013, 42 (9), 3671-3688.

(5) Perez-Ramirez, J.; Mitchell, S.; Verboekend, D.; Milina, M.; Michels, N-L.; Krumeich, F.; Marti, N.; Erdmann, M. Expanding the Horizons of Hierarchical Zeolites: Beyond Laboratory Curiosity towards Industrial Realization, ChemCatChem, 2011, 3, 1731-1734. 
(6) Mitchell, S.; Michels, N-L.; Kunze, K.; Perez-Ramirez, J. Visualization of hierarchically structured zeolite bodies from macro to nano length scales, Nat. Chem., 2012, 4 (10), 825 - 831.

(7) De Jong, K. P.; Zecevic, J.; Friedrich, H.; de Jongh, P. E.; Bulut, M.; van Donk, S.; Kenmogne, R.; Finiels, A.; Hulea, V.; Fajula, F. Zeolite Y with trimodal porosity as ideal hydrocracking catalysts, Angew. Chem., 2010, 49-52, 10074-10078.

(8) Ying, J.; Garcia-Martinez, J. Mesostructured zeolitic materials, and methods of making and using the same US patent 2005, US20050239634.

(9) Li, K.; Valla, J.; Garcia-Martinez, J. Realizing the Commercial Potential of Hierarchical Zeolites: New Opportunities in Catalytic Cracking, ChemCatChem., 2014, 6, 46-66.

(10) Linares, N.; Sachse, A.; Serrano, E.; Grau-Atienza, A.; De Oliveira Jardim, E.; SilvestreAlbero, J.; Cordeiro, M. A. L.; Fauth, F.; Beobide, G.; Castillo, O.; García-Martínez, J. In Situ Time-Resolved Observation of the Development of Intracrystalline Mesoporosity in USY Zeolite, Chem. Mater., 2016, 28 (24), 8971-8979.

(11) Rouquerol, J.; Llewellyn, P.; Rouquerol, F. Is the BET equation applicable to microporous adsorbents? Stud. Surf. Sci. Catal., 2007, 160, 49-56. 
(12) Galarneau, A.; Villemot, F.; Rodriguez, J.; Fajula, F.; Coasne, B. Validity of the t-plot Method to Assess Microporosity in Hierarchical Micro/Mesoporous Materials, Langmuir, 2014, 30 (44), 13266-13274.

(13) Villemot, F.; Galarneau, A.; Coasne, B. Adsorption-based characterization of hierarchical metal-organic frameworks, Adsorption, 2014, 20 (2-3), 349-357.

(14) Thommes, M.; Kaneko, K.; Neimark, A. V.; Olivier J. P.; Rodriguez-Reinoso, F.; Rouquerol, J.; Sing, K. S. W. Physisorption of gases, with special reference to the evaluation of surface area and pore size distribution (IUPAC technical report), Pure Appl. Chem., 2015, 87 (910), 1051-1069.

(15) Coasne, B.; Galarneau, A.; Pellenq, R. J. M.; Di Renzo F., Adsorption, intrusion and freezing in porous silica: the view from the nanoscale, Chem. Soc. Rev., 2013, 42(9), 3821 3832.

(16) Gregg, S. J.; Sing, K. S. W. Adsorption, Surface area and porosity, Academic Press, London, 1982.

(17) Jaroniek, M.; Kruk, M.; Olivier, J. P. Standard Nitrogen Adsorption Data for Characterization of Nanoporous Silicas, Langmuir, 1999, 15 (16), 5410-5413.

(18) Villemot, F.; Galarneau, A.; Coasne, B. Adsorption and Dynamics in Hierarchical Metal- 
Organic Frameworks, J. Phys. Chem. C, 2014, 118, 7423-7433.

(19) Galarneau, A.; Desplantier, D.; Dutartre, R.; Di Renzo, F. Micelle-templated silicates as a test bed for methods of mesopore size evaluation, Microporous Mesoporous Mater., 1999, 27 (23), 297-308.

(20) Galarneau, A.; Iapichella, J.; Bonhomme, K.; Di Renzo, F.; Kooyman, P.; Terasaki, O.; Fajula, F. Controlling the morphology of mesostructured silicas by pseudomorphic transformation : a route towards application, Adv. Funct. Mater., 2006, 16, 1657-1667.

(21) Foster, M. D.; Rivin, I.; Treacy M. M. J.; Delgado Friedrichs, O. A geometric solution to the Largest-Free-Sphere problem in zeolite frameworks, Microporous Mesoporous Materials, 2006, $90,32-38$.

(22) Sing, K. S. W.; Williams, R. T. The Use of Molecular Probes for the Characterization of Nanoporous Adsorbents, Part. Part. Syst. Charact., 2004, 21, 71-79.

(23) Galarneau, A.; Guenneau, F.; Gedeon, A.; Mereib, D.; Rodriguez, J.; Fajula, F.; Coasne, B. Probing Interconnectivity in Hierarchical Microporous/Mesoporous Materials Using Adsorption and Nuclear Magnetic Resonance Diffusion, J. Phys. Chem. C, 2016, 120, 1562-1569. 


\section{Graphical Abstract}

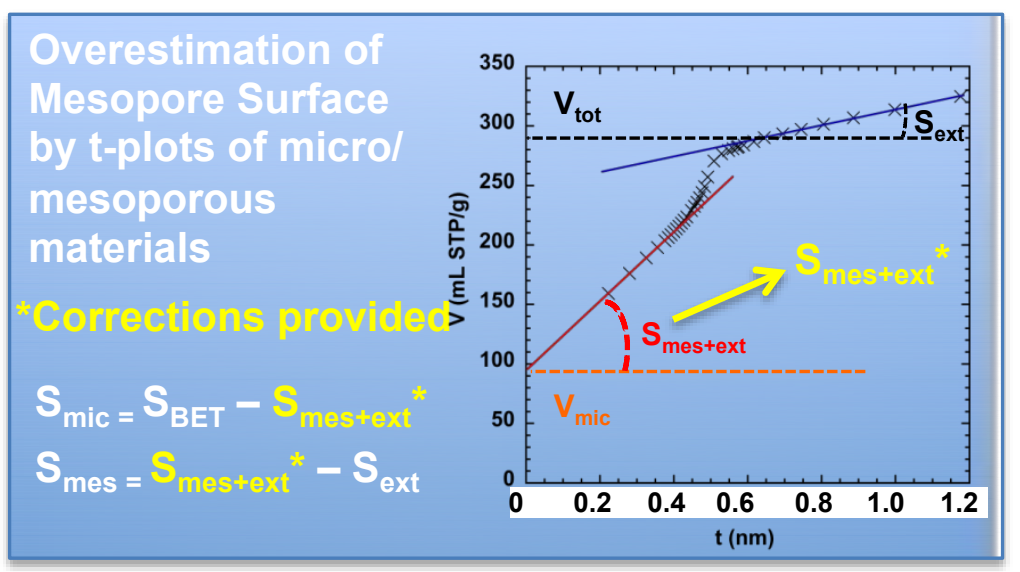

